\title{
STUDY ON THE INFLUENCE OF HIGH HYDROSTATIC PRESSURE ON SOLUTIONS BY THE USE OF AN IMPROVED STATIONARY PLATINUM ELECTRODE POLAROGRAPHY
}

\author{
KANAE HAYASI AND IKUO KÔNO* \\ Department of Physiology, Okayama University Medical School, Okayama
}

In order to interpret various influences of high hydrostatic pressure on living cells and tissues, studies on the change of medium itself are most significant. But such studies are not always so easy, because most physicochemical changes of solution under pressure may be reversible. Consequently studies are few and no definite conclusion has been arrived at.

On the reaction of solutions, Ebbecke (1) deducted from Tamman's (2) report that the strength of weak acid and base increases with a rise in pressure up to some hundred atm. Gibson and Loeffler $(3,4)$ reported the same by means of cresol red and bromphenol blue as reaction indicator, although the change of indicator itself was unknown. Owen and Brinkley (5) contributed a theoretical paper on the effect of pressure upon ionic equilibria in pure water and salt solutions based on the experimental work of Gibson. Johnson et al. (6) calculated that under high pressure the $p_{\mathrm{H}}$ of $1 \mathrm{~m}$ solution of carbonic acid would be more acid than under normal pressure, owing to the promotion of dissociation by pressure. According to the review of Joly (7), the isoelectric point of protein in phosphate buffer solution changes considerably under 10,000 atm.

In our institute, Yamato (8) assumed an increase in the $p \mathrm{H}$ of medium under high pressure. His assumption was based on the observation of an increase in absorption of basic dyestuff fuchsin as well as positive charged colloid-particles to human erythrocytes in isotonic $\mathrm{NaCl}$ solution under high pressure up to 500 $\mathrm{kg} / \mathrm{cm}^{2}$.

Tanbara $(9,10)$ found the shift of the optimum $p \mathrm{H}$ of enzyme action under $1,600 \mathrm{~kg} / \mathrm{cm}^{2}$. pressure and considered that hydrochloric acid and caustic potash solution might change their $p_{\mathrm{H}}$ to a more neutral side under high pressure. But he failed to demonstrate actual changes of $p_{\mathrm{H}}$ of electrolyte solutions by means of a small-sized quinhydrone electrode installed in high pressure bomb. Physicochemical change possibly occurs in electrode itself put under pressure.

According to Okada's $(11,12)$ reports, the electric conductivity of electrolyte solution auguments specially in a weak electrolyte solution with pressure up to $1,500 \mathrm{~kg} / \mathrm{cm}^{2}$. Furthermore, Okada postulates that the $p \mathrm{H}$ of solution undergoes change by high pressure, owing to the change of dissociation of acid or alkali. He has stained various vital plant cells and shown the rise in $p \mathrm{H}$ of basic solu-

Received for publication February 1, 1958.

* 林 香苗, 河野育夫 
tion under high pressure.

Recently Mochizuki $(13,14)$ devised an improved stationary platinum electrode polarography by which the current in the diffusion limiting region $(C)$ is measured in relation with the reduction voltage $(V)$. The current is governed chiefly by the partial pressure of dissolved oxygen. The current is maintained almost constant up to a certain limit of reduction voltage, at which an abrupt ascendance of the current appears. This rise of the current is called the final ascendant and is strongly influenced by the nature of dissolved solution, the $p_{\mathrm{H}}$ of the medium etc. As this apparatus may easily be utilized in studies of solutions under high pressure, it offers us a convenient tool to study effects of high pressure on physicochemical properties of solutions.

In the present investigation, the authors attempted to measure the currentvoltage curve ( $C$ - $V$ curve) of platinum electrode polarograph in various sorts of electrolyte solutions under high pressures, and to search changes of dissociations of these solutions by analysing the curves.

\section{METHOD}

A part of small-sized electrode and polarizing cell are installed in a high

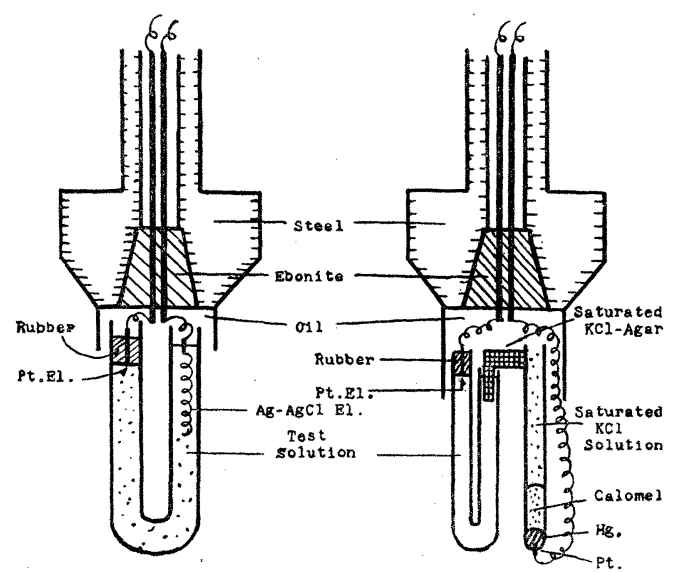

FIG. 1. Schema of both electrodes installed in a high pressure bomb.

In the high pressure bomb filled with mobile oil, polarizing cell is supported with rubber including $\mathrm{Pt}$. electrode sealed in glass. Flat type electrode is about $0.3 \mathrm{~mm}$. wide in diameter and its end is directly exposed to test medium. The surface of this end is polished evenly with red ochre.

As positive electrode, $\mathrm{Ag}-\mathrm{AgCl}$ electrode is not suitable as compared with calomel electrode in respect of perfect nonpolarity, but more favorable for use especially in small space than the latter. Hence the former electrode is mainly used and supplemented by the latter when occasion demands.

Positive electrode is immersed in test solution, and the upper surface of this solution touches mobile oil through which hydrostatic pressure is applied to the test solution. 
pressure bomb as in fig. 1. High hydrostatic pressure bomb is always filled with mobile oil and it is possible to increase the pressure of the content up to the pressure of $2,000 \mathrm{~kg} / \mathrm{cm}^{2}$. by an oil pressure pump. To avoid the contamination of the electrode and polarizing cell by oil, every precaution is taken at each measurement.

For the necessary stability the electrode must be tested within the error of 0.5 per cent and as for the reproducibility $100 \pm 3$ per cent under the normal pressure. Current-voltage curve was obtained by subjecting 0.05 volt each step per 7.5 seconds. Plus 0.5 volt was mainly applied as charging potential.

The solutions examined are those of salts $\left(\mathrm{NaCl}, \mathrm{NaHCO}_{3}\right)$, alkali $(\mathrm{KOH})$, acids ( $\mathrm{HCl}$, Oxalic acid) and Sörensen's phosphate buffer solution of from 5.9 to 8.0. Ringer's solution was also studied as an example of biological fluid.

\section{RESULTS}

1) C-V curve of salt solutions

Fig. 2 shows $C$ - $V$ curves of salt solutions at various concentrations under normal and $1,500 \mathrm{~kg} / \mathrm{cm}^{2}$. pressure.

The value of limiting current proportional to dissolved oxygen quantity and the degree of final ascendant mount nearly in proportion to the applied pressurestrength according to still more detailed data. Such phenomenon is especially apparent in the degree of final ascendant and quite reversible. However, the influence of pressure upon the $C$ - $V$ curve is inferior to that of salt concentration. It is interesting to note that the pressure effect is dominant particulary in the case of dilute solution such as $0.025 \mathrm{M}$ salt solution as compared with the

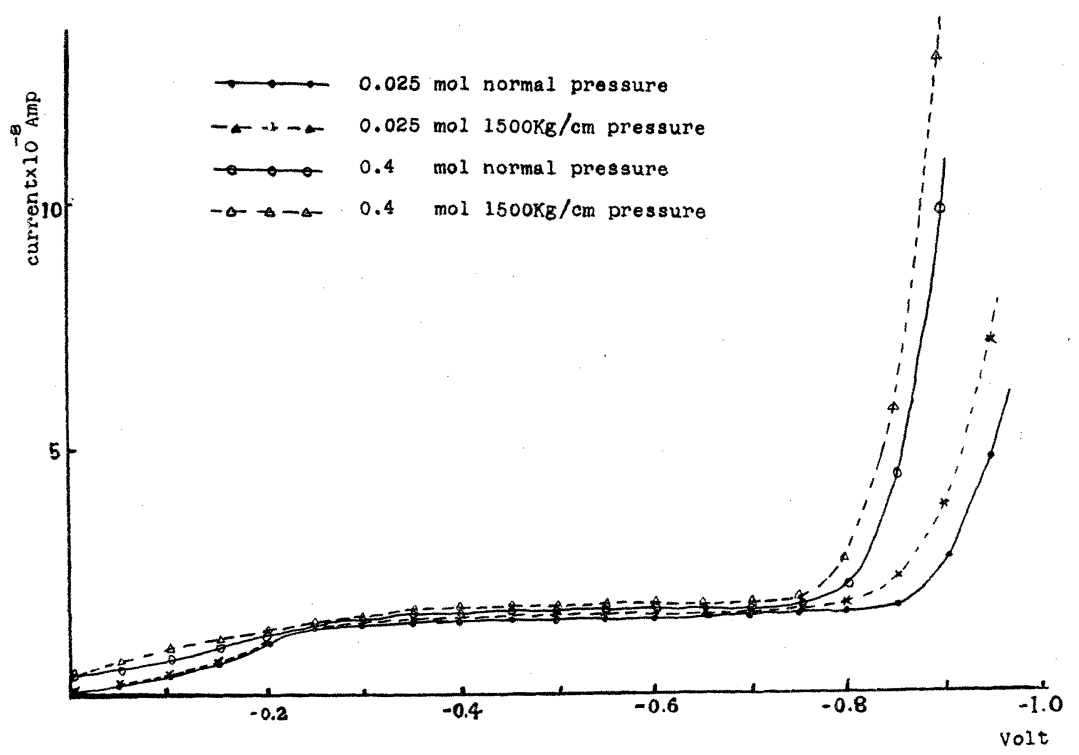

FIG. 2. Influence of high pressure on $C \cdot V$ curve of salt solution. 
effect in more concentrated solutions.

The $C-V$ curve of $1 \mathrm{~N}$ sodium bicarbonate solution (hydrolyzed solution) changes by high pressure as fig. 3 . The limiting current region is extended to positive side and the final ascendant inducing voltage shifts neither to positive nor to negative side. Consequently the form of the $C$ - $V$ curve becomes more typical under high hydrostatic pressure.

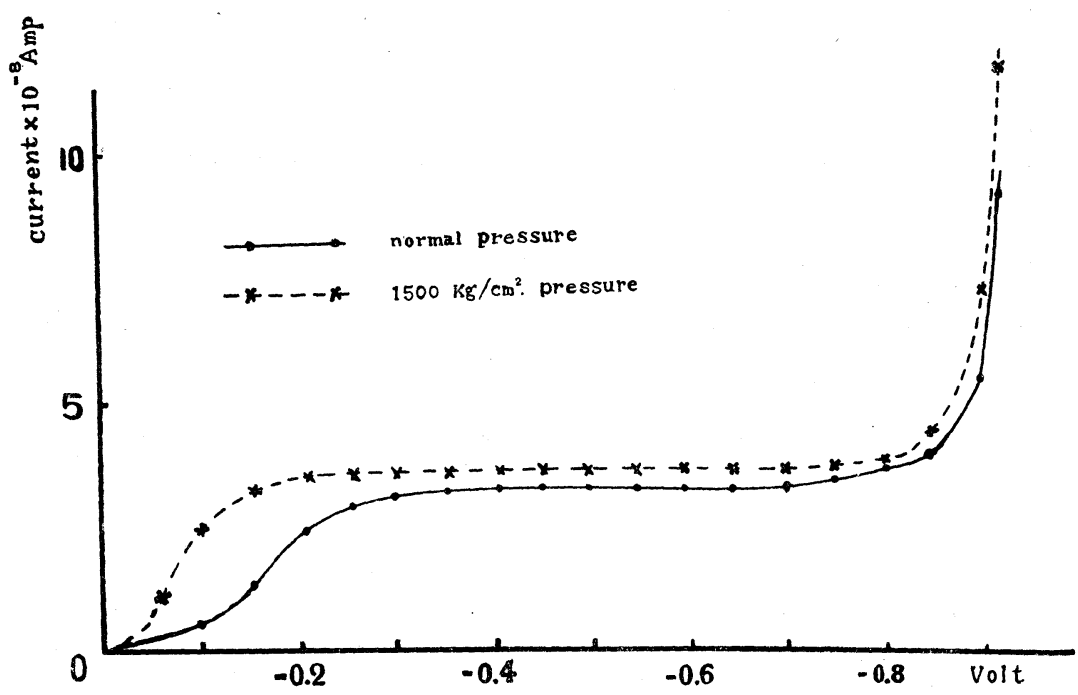

FIG. 3. Influence of high pressure on $C$ - $V$ curve of $1 \mathrm{~N}$ sodium bicarbonate solution.

\section{2) $C$ - $V$ curve of basic solution}

$C$ - $V$ curve of $1 \mathrm{~N}$ caustic potash (diluted twofold with $09 \% \mathrm{NaCl}$ solution) scarecely alters its form by high pressure as fig. 4 .

3) C-V curve of acid solutions

A weak acid solution such as $1 \mathrm{~N}$ oxalic acid changes its $C$ - $V$ curve as if its $p_{\mathrm{H}}$ were decreasing (fig. 5). This change is neacly reversible when applied pressure is removed.

On the other hand, a strong acid solution such as $1 \mathrm{~N}$ hydrochloric acid (diluted twofold with $0.9 \% \mathrm{NaCl}$ solution) scarecely changes its $C \cdot V$ curve by high pressure as fig. 6 .

\section{4) $C$-V curve of buffer solutions}

Under normal pressure, $C$ - $V$ curve of Sörensen's buffer solution series changes its form in accordance with their $p_{\mathrm{H}}$ values. Generally speaking, the lower the solution $p \mathrm{H}$ is, the more the final ascendant inducing potential moves to positive side and the form of the $C$ - $V$ curve becomes a typical as in fig. 7. Such a phenomenon exists under high hydrostatic pressure as well. Effect of high hydrostatic pressure on each $C$ - $V$ curve of buffer solutions of various $p H$ 's as 


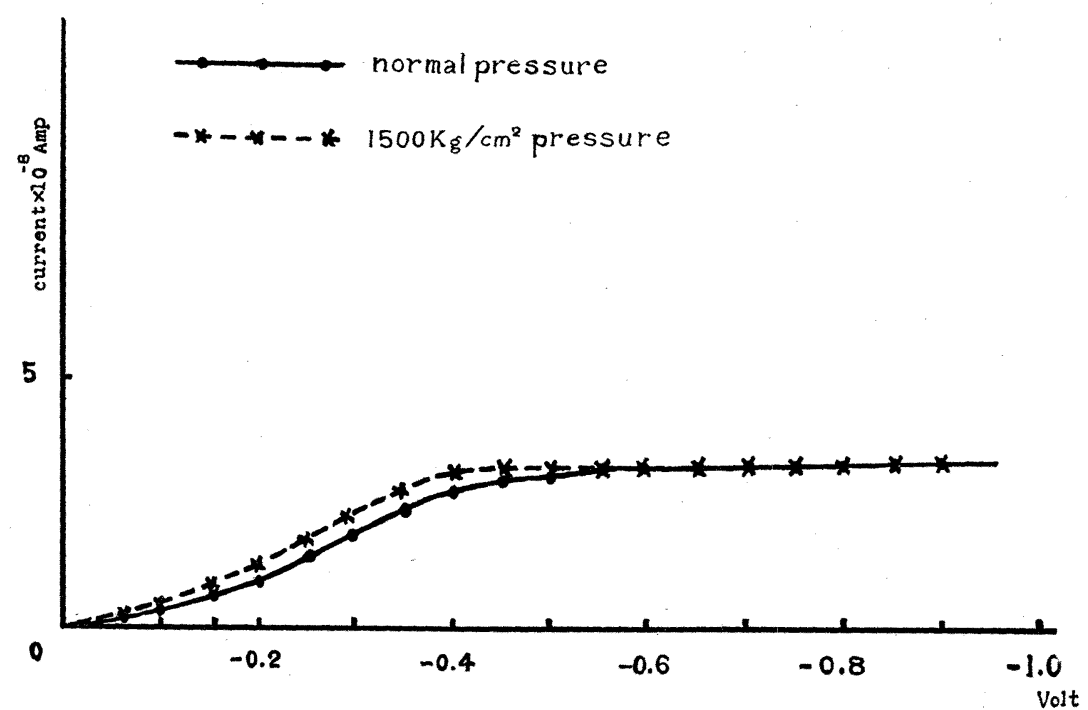

FIG. 4. Influence of high pressure on $C$-V curve of $1 \mathrm{~N}$ caustic potash solution.

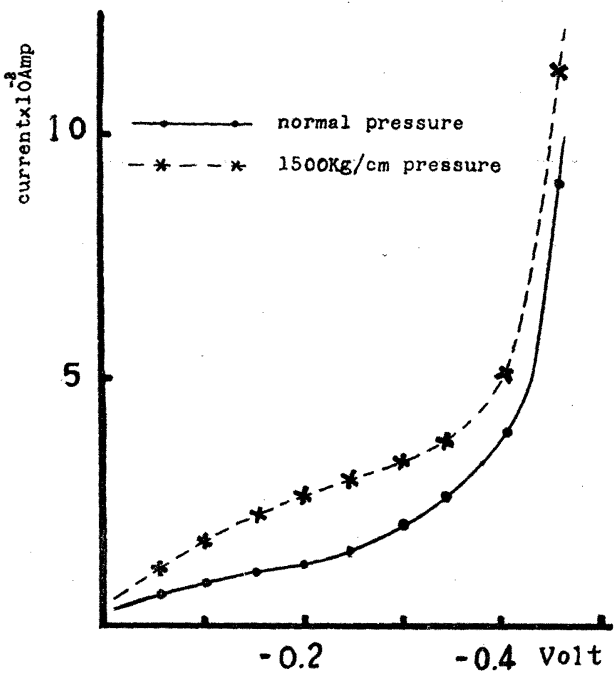

FIG. 5. Influence of high pressure on $C$ - $V$ curve of $1 \mathrm{~N}$ oxalic acid solution. (Sensibility $3 / 5$ )

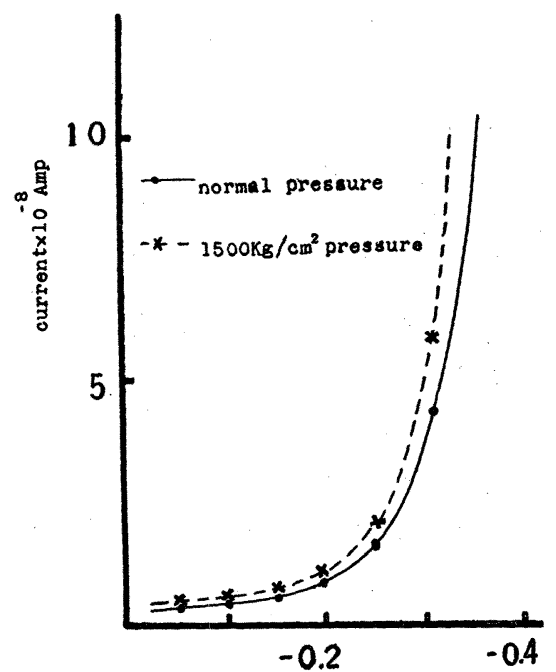

FIG. 6. Influence of high pressure on $C \cdot V$ curve of $1 \mathrm{~N}$ hydrochloric acid solution. (Sensibility $3 / 5$ )

well as Ringer's solution, though they may be not neutral, is confined to the increase in the degree of final ascendant and does not change the potential that induces the final ascendant. Although it is impossible to pursue half-wave potential perfectly by the use of this instrument, it seems that pressure is not effective on half-wave potential apparently in such a buffer solution.

Fig. 8 shows the $C-V$ curve of 0.65 per cent Ringer's solution as an example 


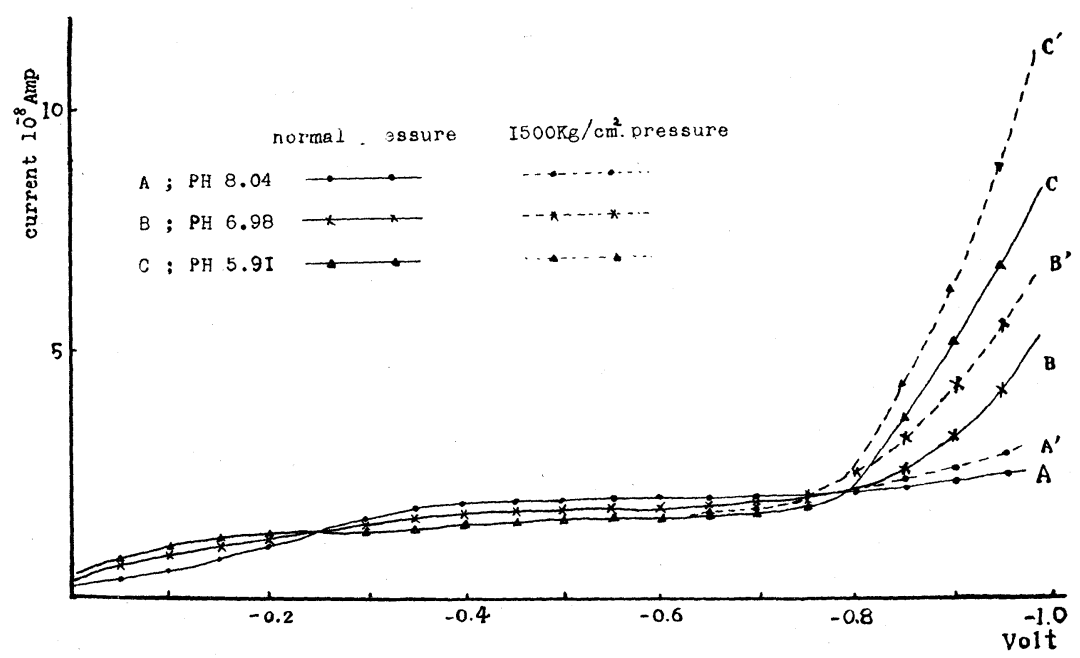

FIG. 7. Influence of high pressure on $C-V$ curve of Sörensen's buffer solution.

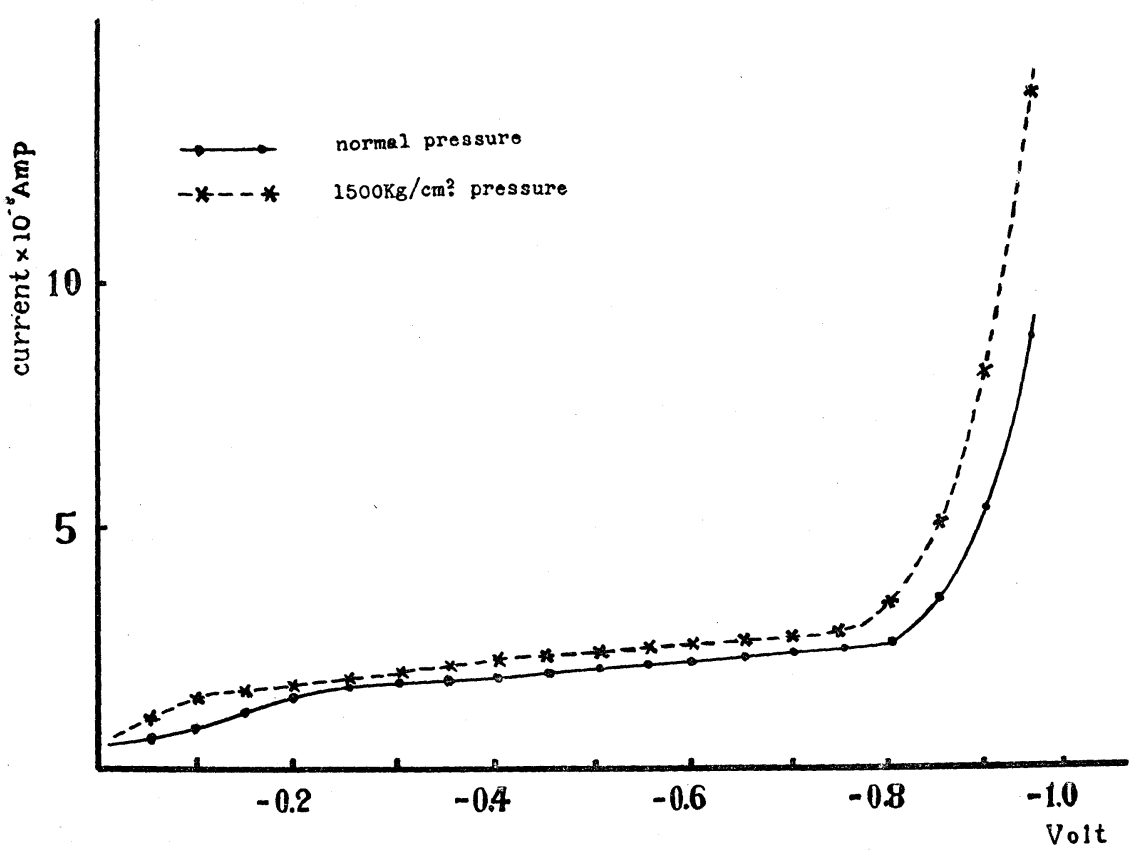

FIG. 8. Influence of high pressure on $C$ - $V$ curve of 0.65 per cent Ringer's solution.

of biological fluid under normal and $1,500 \mathrm{~kg} / \mathrm{cm}^{2}$. high hydrostatic pressure. The value of limiting current and the degree of final ascendant mount nearly in proportion to the applied pressure-strength and quite reversible. Apparently pressure is not effective on both potentials inducing half-wave and final ascendant in Ringer's solution also. 


\section{DISCUSSION}

Concerning the influence of high pressure on the electrode itself, Bridgman (15) reports that alteration of $\mathrm{AgCl}$ from face centered cubic type to body centered cubic type appears under extremely ultra high pressure. This alteration, however, can be disregarded in the scope of our experiment. In conjunction with the $C \cdot V$ curve obtained by our instrument, there is an experiment in which Mochizuki (13) compared the theoretical equation value with experimental equation value about oxygen wave by the same type of instrument with ours and made the two values almost to coincide with each other.

In buffer solution, it is most noticeable that the increase of limiting current value occurs in consequence of an increased dissociation induced by high pressure and the acceleration of reduction is deduced from an increase in the degree of final ascendant.

On the other hand, the effect of pressure is dominant especially on dilute salt solutions. Such results coincide with Owen's theoretical sugguestion, though there might have been some changes in the solubility of carbonic anhydride in our experiments.

Asano and his associates (16) made a report on the relationship between $p \mathrm{H}$ and the $C \cdot V$ curve about some various buffer solutions. By the use of the same type of instrument as we used, they estimated potential value which induces final ascendant, and showed that in most cases hydrogen decomposition voltage changes according to the changes in the $p_{\mathrm{H}}$ of solution. Namely, in acid solution, decompositon of hydrogen occurs at low electric potential in proportion to its acidity. Hence we may consider that in buffer solution high pressure is nearly ineffective on the buffer action.

Concerning non-buffer solution, weak acid solution increases its acidity in proportion to the strength of pressure. But strong electrolyte solutions were scarecely influenced by pressure examined. These $p \mathrm{H}$-changes in solution by pressure owe the changes generally to dissociable weak electrolyte, viewed from the change of the $C$ - $V$ curve.

After all, experimental results obtained under high pressure seem to confirm directly various experiments and hypotheses by predecessors.

\section{SUMMARY}

Using an improved stationary platinum electrode polarography, current voltage curves of buffer and non-buffer solutions were compared under normal and various high hydrostatic pressures.

(1) The effect of high pressure on various concentrated salt solutions is remarkable particularly in dilute solution as postulated by predecessors.

(2) The $p_{H}$ of non-buffer solution undergoes change under high pressure probably owing to the quantity of dissociable weak electrolyte.

(3) Pressure does not influence the buffer action of buffer solution.

(4). Under high pressure it seems in general dissociation increases and reduction is liable to occur. 


\section{REFERENCES}

1. EвBECKe, U. Pflüg. Arch. 157: 79, 1914.

2. TAMMAN, G. Zentr. Bl. Hyg. 45: 171, 1904.

3. Gibson, R. O., Fawset, E. W. And Perrin, M. W. Proc. Roy. Soc. London. 150: 223, 1935.

4. Gibson, R. O. And Loeffler, O. H. Trans. Am. Geophys. Union. 503, 1941.

5. OWen, B. B. ANd Brinkley, S. R. Chem. Rev. 29: 525, 1941.

6. Johnson, F. H., Eyring, H. AND Polissar, M. J. The Kinetic Basis of Molecular Biology. New York: John Willey and sons, Inc., 1954.

7. Joly, M. Progress in Biophysics and Biophysic. Chem. 5: 168, 1955.

8. YAMATO, H. Okayama Igakkai Zasshi 64: 881, 1952.

9. TANBARA, H. ibid. 64: 950, 1952.

10. TANBARA, H. ibid. 64: 955, 1952.

11. OKADA, K. ibid. 66: 2089, 1954.

12. OKADA, K. ibid. 66: 2101, 1954.

13. Mochizuki, M. Monograph Series of Res. Inst. Appl. Electr. 2: 35, 1951.

14. Mochizuki, M. And Bartels, H. Pflüg. Arch. 261: 152, 1955.

15. Bridgman, P. W. Proc. Am. Acad. 72: 63, 1937.

16. Asano, T., Kirikae, H. And Tanaka, A. Bull. Res. Inst. Appl. Electr. 7: 41, 1955. 